Journal of Universal Language 2

March 2001, 61-69

\title{
Like WTO, Why not WCO?
}

\section{Stuart Read}

Hongik University

As the effect of globalization has been to increase the level of language contact between speakers of different languages, English becomes to stand out as the leading world language as people express their need for a common tongue.

However, this paper objects to English as a world language. In addition, this paper is against any ocher natural languages as well as multilingualism. Instead, this paper claims that the adoption of an artificial or "planned" language could a possible solution.

\section{Introduction}

The days that we are living in are made unique by the process of globalisation. Advances in science and technology have brought the four comers of the world closer together than ever before. Wherever people go they want to communicate, and thus globalisation forces us to address issues of communication in a unique way. As the pace of globalisation quickens so the linguistic implications of globalisation become more acute. What are the linguistic implications of globalisation and how should we respond to them?

One of the most profound effects of globalisation has been to vastly increase the level of language contact between speakers of different languages. Out of this context, English is emerging as the leading world language as people express their need for a common tongue. One fifth of the world's population speak English and the demand to learn English continues to grow amongst the remainder (Crystal 1995). It has been also pointed out that English is the 
universal language of the world owing to its strategic asset in the global market and the global lifestyle (Naisbitt 1994:26). It is estimated that over I billion people will be learning English by the year 2000 and Naisbitt and Aburdene (1990) consider English to be the main force for a global lifestyle. The British Council's English 2000 press report put it like this:

"English is the main language of books, newspapers, airports and air traffic control, international business and academic conferences, science technology, diplomacy, sport, international competitions, pop music and advertising."

Coupled with the spread of English as a world language has been the growth of international and supranational organisations as well as a product of globalisation. Organisations, such as the U.N., N.A.F.T.A, A.S.E.A.N., the World Bank, and the E.U., organisations which are often in some part economically motivated, have helped English into its present position. It can be argued that in each of these organisations, along with the majority of big businesses, English is the dominant language; Phillipson and Skutnabb-Kangas (1996) point out,

"It is the language in which the fate of most of the worlds citizens is decided, directly or indirectly."

English presently stands at the top of the world's language hierarchy; this inevitably influences social reproduction and intercultural communication.

\section{Globalisation and Language Rights}

Some have argued that the current dominance of the English language runs contrary to the principles of human rights and English 
expansion in continental Europe as possible treat or blessing (Phillipson \& Skutnabb-Kangas 1997). The People's Communication Charter (Hamelink 1994) calls for national and international language policies that represent people's fundamental right to communicate. The Prague Manifesto of the Movement for the International Language Esperanto states:

"Any system of communication which confers lifelong privileges on some while requiring others to devote years of effort to achieving a lesser degree of competence is fundamentally anti-democratic...."

The unequal distribution of power between languages is a recipe for permanent insecurity, or outright language oppression, for a large part of the world's population.

We maintain that the wide variations in power among languages undermine the guarantees expressed in many international instruments of equal treatment regardless of language.

Recent studies have shown that examples of language situations that uphold these principles are few and far between. Scossa argues that the English-only policies of US governments and institutions served to undermine civil liberties nominally guaranteed in the Constitution; while Moore considers the dismantling of Australia's National Language Policy, with its explicit support of linguistic diversity as a societal resource, as being opposed to basic human liberties.

Most would accept that, in an ideal world, participants in communication would be in a position of equality and that a respect for language rights should be a pillar upon which language policy, be it at the national or international level, is built upon. Given this state of affairs, we need to ask whether or not the current trends are desirable and whose interests the diffusion of English is serving. More specifically we should investigate whether the spread of English is opposed or complementary to the maintenance of indigenous cultures and the protection of language rights. 


\section{Objections to English as a World Language}

The forces that have established English as today's world language are not compatible with the concept of language rights. The British Council backed book. The Future of English?, suggests that the global use of English today has been largely established upon the languages and cultures of many parts of the world. Such imperialism had devastating effects upon the languages and cultures of many parts of the world. Is the situation really any different today? The biggest influence behind the propagation of English is economics. This seems to be acknowledged by the British Council, who in the press pack for the English 2000 project, claim that one of its aims is "to exploit the position of English to further British interests," and that "speaking English makes people open to Britain's cultural achievements, social values, and business aims". Graddol admits that "proficiency in English may yet be one of the mechanisms for dividing the haves from the have-nots". History suggests that linguistic imperialism should be actively resisted.

Other objections have been made about the position of English as a world language. The Japanese writer Tsuda has complained:

"Americans take it for granted that foreigners should speak English. That is, linguistic imperialism and Americans should give up that idea. I believe Americans respect fairness, but as far as language is concerned, they are not fair. For example, the U.S. Ambassador has never held a press conference in Japanese."(Tsuda 1994:59)

Voltz (1994) points out that speakers of languages other than the dominant ones (i.e. English) are at a disadvantage and refers to complaints of this nature that the German government has made to the E.U. Is it fair to oblige scholars to publish or address conferences in English? While the British Council and others seem aware of the advantages that the diffusion of English would bring to 
them, native speakers of other languages are also aware of the disadvantaged position they would be left in. Accepting that in the age of the global village there needs to be a world-wide language to facilitate communication, is there any alternative to English?

\section{Objections to Any Other Natural Language as a World Language}

The aforementioned criticisms of English as a world language would bear relevance to any other natural language that were to become dominant in the future, be it French, German, Swahili or Japanese. The aforementioned criticisms do not object to the inherent nature of English, but rather to the unequal power balance that its dominant position produces resulting in the loss of language rights for large parts of the world community. It is the position of English that is unsatisfactory not the language itself and the above objections would be equally salient to any other natural language that established itself at the top of the world language pecking order. The existence of one dominant language in the world, by definition, causes a divide between the dominator and the dominated. This is linguicism, defined by Skuttnab - Kangas as:

"Ideologies, structures, and practices which are used to legitimate, effectuate and reproduce an unequal division of power and resources (material and immaterial) between groups which are defined on the basis of language." (Skutnabb-Kangas 1988:13)

\section{Objections to Multilingualism}

Both the U.N. and the E.U. claim to be multilingual organizations respecting the democratic rights of all languages. While this is a commendable stance, what does it mean practically? The E.U. 
recognizes 11 languages under its multilingual policy, but as Phillipson and Skutnabb-Kangas (1996) point out, even this is inconsistent with language rights. Catalan is a language spoken by 6 million people under E.U. legislation (more than Danish and Finnish), yet it is not one of the E.U/ s 11 languages. The E.U., therefore, enforces the loss of rights upon this community. The U.N. recognizes only six official languages (Arabic, Chinese, English, French, Russian, and Spanish), so speakers of ocher tongues are denied language rights. The reason for limiting the U.N. to six recognized languages is a practical one. The U.N. policy implicitly realizes that multilingualism, with absolute equality for all languages, is a practical impossibility. Its present policy is a compromise between democratic language rights and plausible practice.

Other international organizations claim to support the position of multilingualism, but in practice English remains dominant in most of them. At best, such organizations can only hope to create a language hierarchy that is broad based. From the viewpoint of language rights, this may well be preferable to English (or any other language) as a simple world language, but we may well ask if a superior solution is still available. Phillipson and Skutnabb-Kangas (1997) conclude that "recognizing linguistic human rights involves accepting the reality of linguistic hierarchies and the need to mitigate them". Can we, therefore, find a solution to the need for a world language without creating a language hierarchy?

\section{Is There a Role for an Artificial Language?}

The adoption of an artificial or "planned" language could, perhaps, provide the solution. Proponents of Esperanto, the world's most widely spoken artificial language, would claim exactly that certainly there is some potential in their argument although certain objections to Esperanto as a world language do also exist. By contrast, Esperantists claim that their language "allows communication on an 
equal footing". However, this claim seems to ignore the European bias upon which the language was created. It uses a regularized set of word roots almost exclusively taken from the Romance family of languages. One Esperanto speaker and supporter admit that "anyone who has studied a western European language finds something familiar to assist in the learning of Esperanto". Once more the advantage is with the Western world (though at least here South Americans and many Africans can join them).

Many scholars have called for the development of a planned language which is more international and more logical than Esperanto. The Esperantists counter that this would interfere with "the establishment of a large community of speakers". This is not true. The development of a new planned language would not take Esperanto away from its speakers. The community would still exist. (It may also be a matter of debate whether or not the 2 million speakers of Esperanto can rightfully be called a "large" community of speakers). Esperantist's own criteria for justifying the development of a new planned language is for it to be "visibly and profoundly an improvement over Esperanto of prodigious proportions". In view of the vast amount of linguistic research that has taken place since the formation of Esperanto and the advances in computer technology this kind of improvement seems not only possible, but should be considered likely and presents a challenge to the linguistic profession.

\section{Summary and Conclusions}

Graddol estimates that, if current trends continue, we will experience the loss of 3,500 languages in the next 50 years, almost half of the languages in existence today. He considers that this change to the linguistic landscape will be irreversible. Because of its position in business and science in particular, English is likely to strengthen in its dominance as a world language and influence the 
language ecology in ways that disadvantage non-native speakers.

A neutral planned language, specifically designed to engender egalitarian communication, could be implemented internationally in such a way that communication is facilitated across cultures and language rights of the minority are upheld. However, such a scenario presents us with the question of how such a language could be implemented. Esperanto has struggled to find more than 2 million speakers in over 100 years, but the globalisation effect could considerably speed up this process, especially in the advent of internet technology. Jordan, a proponent of Esperanto confesses, "Of course, Esperanto has not succeeded in achieving sufficient international visibility to be used in all the contexts where it would be useful. At the moment it seems unlikely that it ever will'. We must heed the call of Phillipson and Skutnabb-Kangas (1997) when they say, "Language professionals must consider how to promote a better understanding of language policy issues amongst politicians and bureaucrats".

Is it not time for the development of an international body to oversee the implementation of a world-wide language policy that embraces the principle of equal opportunity for all regardless of mother-tongue, and upholds the values of language rights?

\section{References}

Crystal, David. 1995. The English Language. Cambridge.

Hamelink C. 1994. Trends in world communication: On disempowerment and self-empowerment. Penanag. Malaysia: Southbound \& Third world Network.

Naisbitt, John. 1994. Golbal Paradox. William Morrow and Company Inc., New York.

Naisbitt, John \& Aburdene. 1990. Megatrends 2000. William Murrow 
and Company Inc., New York.

Phillipson, Robert \& Tove Skutnabb-Kangas. 1997. "Human Rights and English in Europe, , Wold Englishies, vol. 16 n.1 (March 1997) 22-43.

. 1996. "English Only Worldwide or Language Ecology?, TESOLQuarterly, vol.30 n.3 (August 1996) 429-52.

Tsuada, Y. 1994. The diffusion of English: Its impact on culture and communication. Keio Communication Review 16,49-61. 